\title{
The Liminality of Temporary Agency Work: Exploring the Dimensions of Danish Temporary Agency Workers' Liminal Experience
}

I Dr. Ingo Winkler'

Associate Professor in Organization Studies, University of Southern Denmark, Denmark

I Mustafa Khalil Mahmood

PhD student, University of Southern Denmark, Denmark

\begin{abstract}
The concept of liminality refers to the experience to be betwixt-and-between social structures and the associated positions, statuses, and roles. We advance the original use of the concept by introducing the various meanings that the experience of being in a liminal state can take. Drawing on political anthropology we identify the dimensions of 'types of subjects,' 'time,' 'space,' and 'scale' in order to analytically unlock the liminal experience. Exemplifying our concept we present the findings from an own study of temporary agency workers in Denmark. Exploring the workers' interpretations allows us to illustrate to what extent their employment situation constitutes a multi-dimensional liminal experience between established social structures and employment categories. The article emphasizes the complexity of the liminal experience. Theoretically and empirically, we show the many meanings along which liminality can unfold in organizational and work-related contexts. We argue that future studies should explore the various dimensions in other contexts of passages from one relatively stable state to another. In doing so, similarities and differences between various liminal experiences and the role the various dimensions play could be identified.
\end{abstract}

\section{KEYWORDS}

Temporary agency work / temporary work / flexible employment / liminality / Denmark

\section{Introduction}

ver the years, research on temporary agency work has led to an impressive stock of knowledge (see the recent review of Håkansson et al. 2013). Previous research focused on the triadic arrangement between the temporary work agency, temporary workers, and the organization making use of temporary workers (i.e., the user-firm). Typically, prior research tended to apply concepts from traditional full-time and permanent work to the context of temporary employment (Ashford et al. 2007; Felfe and Franke 2010; Guest 2004). Hence, established assumptions are deployed to study flexible and atypical forms of employment. However, there is an ongoing debate to what extent traditional theories and concepts from Organizational Behavior and Human Resource Management could explain the particular context of non-standard employment,

1 E-mail: inw@sam.sdu.dk 
which is rather different to that of permanent employment (Ashford et al. 2007; Connelly and Gallagher 2004; De Cuyper et al. 2008). Guest (2004) argues that “(i)n this changing context, it is increasingly likely that the analytic frameworks that have served us well over the years are less able to account for and explain contemporary employment relations behavior in organizations. Arguably, therefore, we need rather different frameworks to explore the 'new' employment relations" (p. 542, emphasis as original).

In terms of theorizing temporary agency work, such a framework needs to consider the circumstance that workers are employed by a temporary work agency in order to be leased out to perform work at a user-firm. Therefore, the agency adopts the formal responsibilities of the employer but it is the user-firm's responsibility to manage the temporary agency workers on a daily basis (Håkansson et al. 2012; Storrie 2007). Due to this arrangement and the fact that the agency and the user-firm are engaged in a business relationship (Håkansson and Isidorsson 2012), temporary agency workers frequently find themselves in a liminal situation, hence, in-between established employment categories and institutional structures (Garsten 1999; Smith 1998). On the one hand, they are not considered fully integrated employees of the temporary work agency but rather are only part of the agency's business. On the other hand, they do not belong to the userfirm but frequently experience to be outsiders to the company they are leased to. They do not benefit from the structural bonds created by permanent employment, yet, at the same time they are expected to demonstrate loyalty to both the agency and the user-firm (Garsten 1999; George and Chattopadhyay 2005; Gossett 2006).

The aim of this article is to investigate the many dimensions of temporary agency workers' liminal experience. We build upon the original concept of liminality provided by Turner (1967), the multi-dimensional concept of liminality developed by Thomassen (2009), and Garsten's (1999) initial research on the conditions and consequences of liminality for temporary agency workers. Taking temporary agency workers in Denmark as the example, we illuminate the dimensions of their liminal experience with temporary agency work.

Emphasizing liminality as constituting a multi-dimensional concept, our article firstly contributes to a better understanding of the complexity of liminality, a concept that becomes more and more popular within the area of organization studies (e.g., Beech 2011; Borg and Söderlund 2014; Ellis and Ybema 2010; Eriksson-Zetterquist 2002; Tempest and Starkey 2004). Secondly, our study shows how the various meanings of liminality constitute the complex nature of the experience to be a temporary agency worker. Although temporary agency work has been previously conceptualized as liminal situation (Garsten 1999), our study demonstrates that to be liminal forms an experience that plays out along several dimensions. Hence, temporary agency work constitutes the workers as liminal personae, experiencing to be betwixt-and-between at various places in their work and life, during particular moments or longer periods, to various degrees, and at both individual and collective levels.

We continue describing the concept of liminality and its application in both organizational research and temporary agency work research. We introduce thoughts from political anthropology in order to elaborate on the many dimensions, hence, many meanings of the experience to be in a liminal state. Afterward we introduce our study on temporary agency workers in Denmark. We exemplify the various dimensions of their experience to be betwixt-and-between. Discussing our findings, we emphasize the complexity of liminality and the contribution of understanding its numerous facets. 


\section{Liminality and Temporary Agency Workers as Liminal Subjects}

Liminality as a state to be in-between social structures and the associated positions, statuses, and roles constitutes a concept that has been popularized in anthropology through the writings of Victor Turner $(1967,1969,1970)$. He draws on Arnold van Gennep (1909/1960), who theorized liminality as the middle stage of a three-step sequential process of ritual transition from one relatively stable social position (i.e., one world) to another. This transitional state follows a stage of separation from previous sociocultural states (such as boy, girl, newcomer) and is followed by a stage of integration into the new socio-cultural setting and therefore new, relatively stable states, such as man, woman, member (Turner 1967).

Turner was particularly interested in "the nature of 'interstructural' human beings" (Turner 1967, p. 93, emphasis as original), hence, the liminal period and the state of transition. He holds that during the liminal state the characteristics of the passenger become ambiguous as "he [sic!] passes through a cultural realm that has few or none of the attributes of the past or coming state" (Turner 1969, p. 94). Turner argues that liminal persons become structurally invisible as the individuals or the group slip through established systems of social classification (e.g., being neither boy nor man). In Turner's words: "The attributes of liminality or of liminal personae ('threshold people') are necessarily ambiguous, since this condition and these persons elude or slip through the network of classifications that normally locate states and positions in cultural space. Liminal entities are neither here nor there; they are betwixt and between the positions assigned and arrayed by law, custom, convention, and ceremonial” (1969, p. 95).

To be betwixt-and-between means that liminal persons have a physical reality, but no social reality since they are no longer classified through previous categories nor yet classified by a new classification system (Turner 1967). They therefore lack status, power, rank, or insignia (Turner 1967, 1969). Thus, Turner associates liminality with marginality and inferiority. However, liminality constitutes an ambivalent state of being that also offers a creative space, where growth, transformation, and the re-formulation of former patterns occur (Turner 1969). Therefore, liminal persons, on the one hand, disappear from the conventional systems of classifying social positions, which relates liminality to deep anxiety and potential suffering for all those who are in such a state (Szakolczai 2009). One the other hand, being liminal creates space to contemplate and experiment with established social structures, hence, this state contributes to creativity (Szakolczai 2009). Therefore, liminality constitutes a state of contingencies, where reality can develop in different directions (Garsten 1999; Thomassen 2009).

During the past 15 years or so Turner's concept of liminality attracted attention within the domain of organization and work-related studies. Scholars particularly emphasized the condition of being liminal while putting less focus on liminality as a stage within the process of transferring from one stable state to another (Beech 2011). With a few exceptions (Beech 2011; Eriksson-Zetterquist 2002; Trice and Beyer 1993), the concept of liminality has been employed in order to understand the meanings of being in-between institutionalized arrangements, taken-for-granted socio-cultural structures, and established social positions. In so doing, previous research applied the notion of liminality in order to grasp the position of consultants as neither insiders nor outsiders (Czarniawska and Mazza 2003; Sturdy et al. 2006, 2009), to investigate identity re-construction due to imposed organizational change (Beech 2011), to explore the 
effects of liminal episodes on individual and organizational learning (Tempest and Starkey 2004), to render the period of entering an organization as a ritual passage (Eriksson-Zetterquist 2002), and to illuminate the in-between position of inter-organizational relationship managers (Ellis and Ybema 2010). With regard to flexible forms of employment, Borg and Söderlund (2014) investigated project workers' technical and social liminality and Garsten (1999) studied temporary agency workers as liminal subjects in flexible organizations.

Garsten's thoughts are particularly relevant for this article. She studied the consequences liminality has for temporary agency workers. "Lacking the structural bond created by a regular employment position, yet drawn into extended circles of loyalty, temporary employees share some of the interstructural and ambiguous characteristics of liminality" (Garsten 1999, p. 603). Temporary agency workers are neither employees of the user-firm, even though they perform the work there, nor do they have a member status at the agency, despite being employed there. They are, thus, in-between the temporary work agency and the user-firm, neither full insiders nor complete outsiders, but always in-between being employee and labor resource. Because temporary agency workers do not experience affiliation to a particular organization, they are liminal which, in turn, results in ambiguity with regard to where they belong, who they are, and how they should respond to their employment situation. Following the notion of Turner that liminality constitutes an ambivalent state, Garsten argues that being liminal could have multiple meanings for temporary agency workers. "The status of being 'a temp' is often a transitory position, open to definition. It may turn out to be a road to permanent employment, an explorative phase in the sphere of work and organization or a passage to a shift in career. It may likewise prove to be a dead-end street, with an increased sense of marginality in relation to organizational resources and to the labor market" (Garsten 1999 , p. 603). To this extent, temporary agency work, on the one hand, may constitute a stepping-stone into permanent employment (Connelly and Gallagher 2004; De Cuyper et al. 2008). It could therefore form a defined liminal period during which temporary agency workers are "in transit between relatively fixed social structures" (Garsten 1999, p. 605). On the other hand, temporary agency work could become a permanent situation (Garsten 1999). Not being able or not being willing to manage the transfer into permanent employment, temporary agency workers could find themselves within an ongoing state of being in-between, which is related to substitutability and an enhanced sense of reflexivity (Garsten 1999).

Previous research on liminality in organizational context put emphasis on the two dimensions of space and time. For example, Sturdy et al. (2006) investigated business meals between consultants and clients pointing out how these situations constitute a liminal time space, as they are between work and leisure. Beech (2011) researched how liminality contributed to identity-work of employees within periods of organizational change in two service organizations. Garsten (1999) saw temporary agency workers as being betwixt-and-between social structures, yet, also emphasized the temporal nature of this employment and the associated liminal experience. Emphasizing space and time, previous research follows Turner, who himself referred to liminal people as situated between social categories during the period of transition. However, after reviewing the uses and meanings of liminality, Thomassen (2009) argued that there are more meanings of the liminal experience since "liminality refers to any 'betwixt and between' situation or object" (p. 16, emphasis as original). On the one hand, he proposes further distinctions 
of both the spatial and temporal dimensions of liminality. On the other hand, he suggests further dimensions, such as types of subjects, scale, and the distinction whether liminality is artificially produced or simply happens.

Experiencing liminality with regard to space, according to Thomassen (2009), can be further classified into (a) specific places (or thresholds), (b) areas and zones, as well as (c) countries and larger regions. To this effect, liminality can relate to specific places, such as the physical separation of the holy from the sacred in a ritual, parts of the human body, or certain items signifying in-between in a classification schema. Other examples are the workplace or the work unit during times of entering a new organization (Eriksson-Zetterquist 2002) and the restaurant as in-between work and leisure space, where business meals between consultants and clients take place (Sturdy et al. 2006). Border areas between countries and direct transit areas at airports constitute examples of areas and zones (Thomassen 2009). One could add the spatial area of the working environment and the area outside work, in which the private life takes place as further examples of areas or zones. In terms of larger regions, Thomassen (2009) refers to, for example, Iona in Ancient Greece being in-between the Near East and Europe. Nations that are in a state of societal transition also constitute larger regions where people experience liminality.

According to Thomassen (2009), experiencing liminality with regard to time can be divided into (a) particular moments (such as sudden events, when one realizes to be in a liminal situation), (b) longer periods (weeks, months, years), and (c) epochs (decades, generations). Referring to the temporal dimension, Ellis and Ybema (2010) showed that the position of inter-organizational relationship managers turned out to be a liminal position (not belonging to any of the firms, while managing the relationships between them) ongoing for a longer period. Garsten (1999) argued that temporary agency work could turn into a dead-end street with the liminal experience becoming manifested for years.

In addition to time and space, Thomassen (2009) introduces 'types of subjects' as another dimension of the liminal experience. Different types of subjects may experience liminality, such as (a) single individuals, (b) social groups, or (c) whole societies and entire populations. Embarking on a university in Denmark five years ago, I experienced to be in a liminal situation, since it took me some time to make the passage from a newcomer to an accepted member of the department. Temporary agency workers as social group experience liminality due to the particular structural conditions this type of employments creates for them (Garsten 1999). It is not difficult to think of whole societies experiencing to be betwixt-and-between while, for example, making the transition from an authoritarian system to a different form of government.

Finally, Thomassen (2009) introduces the dimension of scale, referring to the degree of the liminality experience. The intensity of the liminal experience with regard to specific places and times varies. There are occasions and situations during which "liminal experiences become intensified" (p. 17). Completing the project may constitute such a moment for project-based workers (Borg and Söderlund 2014) as this circumstance emphasizes the temporariness of their occupation. In terms of temporary agency work, being between established structures may be a permanent experience during this kind of employment. However, during particular moments the liminal experience becomes more intense. Such moments may be situations when temporary agency workers learn that they are not invited to annual Christmas parties or other social events at the user-firm, because temps do not belong to the user-firm. 
Thomassen (2009) emphasizes the somewhat artificial nature of his distinction. It is, for example, not possible to distinguish 'places' from 'areas' or 'moments' from 'periods' in an absolute way. However, the various dimensions elucidate that the experience of liminality has many dimensions and, hence, many meanings. Therefore, studying liminality should not be reduced to a rough and, in a way, simplified time and space distinction. Instead, the understanding of what it means to be liminal could benefit from investigating the liminal experience along various analytical dimensions. Moreover, how these dimensions coalesce within the lived experience to be in-between and how they thereby constitute the multi-facetted experience of being liminal contributes to better comprehending the complex nature of liminality.

Taking temporary agency workers in Denmark as the example, our study illuminates the dimensions of their liminal experience with temporary agency work. Applying Thomassen's (2009) framework and relating to Garsten's (1999) work on the conditions and consequences of liminality for temporary agency workers, we further elaborate the many facets the liminal experience can take.

\section{Statement of Method}

The study followed an interpretivist orientation, as we were interested in the meanings that temporary agency workers construct of their experiences made at the different user-firms. We conducted semi-structured interviews with 30 temporary agency workers from four agencies in the region of Southern Denmark. Access to the interview partners has been gained with the assistance of the temporary employment agencies. We have been able to receive contact data for a number of workers. With some of them we arranged individual interviews. In no case did the agency receive any feedback about who of the workers finally had been interviewed. This ensured anonymity despite the fact that the agencies were involved in mediating to the workers.

All of the workers in our sample were so-called non-permanent temporary agency workers. About $95 \%$ of the Danish temporary workers are non-permanent temporary agency workers (Scheuer 2011). They are employed by the agency only during the period the agency contracts them to a user-firm. Between assignments the temporary agency workers are unemployed and, in our cases, rely on unemployment benefits. Only a small proportion of the temporary workers in Denmark are permanent temporary agency workers (Scheuer 2011), meaning that they are regularly employed by the agency and receive a guaranteed salary also during time when they are not leased to a user-firm.

In the beginning of our study, we selected the participants randomly. This was followed by a more careful selection according to the interview partners' age, length of employment, gender, and occupation. In doing so, we enriched our sample aiming at a greater variety. Although one may argue that this resulted in a certain lack of focus, as for example only concentrating on younger male construction workers would lead to more specific insights, we hold the opinion that a greater extent of variety in our sample enabled us to explore the broader spectrum of meanings that temporary agency workers assign to their employment situation and the experiences made in the user-firms. Our sample is composed of both male (11) and female (19) temporary agency workers. We interviewed workers between the age of 20 and 60 . Their experience with temporary agency work varied from one to more than four assignments, the majority having had 
between two and four. They worked in various occupations, such as manufacturing, cleaning, construction, clerical work (e.g., marketing, logistics, IT, administration).

Our informants' motivation to engage in temporary agency work followed three particular motivations. Firstly, to work for a temporary work agency for them constitutes a means to find a permanent employment (Jahn and Rosholm 2010). Secondly, this type of employment constitutes the possibility to have a higher income than one would receive from relying on unemployment benefits. Thirdly, temporary agency work enables to extend the period for being eligible to receive unemployment benefits from two up to three years. Thus, one could stretch the period in which one benefits from financial support from the unemployment insurance fund ('A-kassa' in Danish) by being temporarily employed by a staffing agency in order to work at a user-firm. This, in turn, means that one has more time to find a permanent appointment.

During the interviews we focused on what previous research (e.g., De Cuyper et al. 2008; Garsten 1999; Guest 2004; Smith 1998) regarded as typical worker-related aspects of temporary employment and temporary agency work in particular. Hence, our study did not follow a pure inductive logic as we introduced our respondents to themes from previous research. Amongst other topics, we talked about their general understanding of this kind of occupation, investigated their motives to engage in temporary agency work, discussed the difference between work environments at user-firms, addressed the temporary agency workers' relationship to regular employees, spoke about how temporary agency work influences their work attitudes, and explored to what extent this employment affected their private lives. We decided to include these topics in order to stimulate our informants' reflection. To this extent, we built on Turner's (1967) notion that being betwixt-and-between causes people to reflect upon their society, their culture, and their place within the social structure.

Analyzing the interviews we decided for an approach that combines individual and collective analysis of the material. Each of us analyzed the interviews individually; however, we also engaged in discussing our results and, thus, jointly constituted meaning of what the interview partners said. This procedure ensured establishing research quality through investigator triangulation (Denzin 1978). During the initial coding we followed the topics addressed in the conversations (Ryan and Bernard 2003). We analyzed the material following the themes that we brought up during the interviews. We added more topics applying an open coding procedure (Strauss 1990), hence searching for themes that emerged from the material (Creswell 2013). In doing so, we learned that our informants did not only talk about their particularly experiences in the user-firm but narrated their theory of what it means to be a temporary agency worker. Hence, their answers covered the broader context of their life situation and not only the employment situation. During the analysis we frequently discussed and refined our interpretations (Seale 1999; Charmaz 2006). We constantly compared our interpretations in order to ensure coherence during our data analysis. We were aware that we as the researchers were also authors of this interpretation (Cunliffe 2002). The frequent discussions, ongoing comparisons, and, thus, continuous re-interpretation of the interviews, step-by-step led to a rich picture of what it means to be a temporary agency worker in Denmark based on the experiences our informants narrated.

The picture that we paint in the following part of the article represents the varieties of experiences that our informants brought up during the interviews. However, this picture is neither complete, i.e., including all aspects of temporary agency work in 
Denmark, nor is it exhaustive, i.e., representing the experiences of all Danish temporary agency workers. Rather, it is necessarily selective due to our theoretical interest and the distinct set of informants we had access to. Nevertheless, the picture we paint is both insightful and relevant as it illuminates voices from Danish temporary agency workers illustrating the dimensions of their liminal experience.

\section{The Dimensions of Danish TAWs' Liminal Experience-An Empirical Illustration}

\section{Types of Subjects-The Collective and Individual Liminal Experience ofTAWs}

In terms of Thomassen's (2009) dimension of 'types of subject,' the workers in our study experienced liminality both as a category and on a more individual level. Our participants as a category (i.e., a particular category of flexible employees) experienced being in a liminal state. This experience has three particular notions within the Danish context.

Firstly, although the workers perform their work at the user-firm, they frequently experience non-membership to the company they are leased to. They do not become insiders even though they become part of the workforce of the user-firm for a certain period. During this period they cooperate with the permanent staff while doing their task. However, they always have the feeling that they do not belong to the user-firm's staff but are only affiliated with the firm and its employees during the time they work there. Hence, they are always the newcomers, the "strangers in the workplace" (Garsten 1999, p. 607), the ones who will leave soon and, therefore "could make no claims on the prerogatives of membership" (Barley and Kunda 2006, p. 49). As one of them put it: "(You) never get the chance to communicate as colleagues, because she/he sees you as a outsider and not part of the team" (E10). Within the Danish workplace culture this poses a particular issue. Being a non-member implicates being excluded from the workplace community at the Danish user-firm. This experience, on the one hand, contradicts the strong sense of togetherness (i.e., 'fællesskab'), the important notion of belonging to a community of people one shares similarities with, one is accepted by, and one has a somehow equal status within the culture of the Danish society (Jenkins 2011; Nørmark 2011). On the other hand, belonging to a group and contributing to this group are strong elements of the Danish workplace culture too (Yüksekkaya 2007). However, due to their temporary state, temporary agency workers are denied participating in social activities within the user-firm, although these activities and the participation therein are seen as crucial to establish and maintain social bonds between employees in Danish workplaces. Furthermore, "(e)ven though you know that some of the parts need optimization. But they are not ready for it, or they don't want to hear from you, you're just a flexible employee" (D10). Not being accepted as full members of the user-firm, temporary agency workers often have no voice in discussions even if they may have something to contribute.

Secondly, in some cases (especially in the smaller and local agencies where our participants have been employed) the temporary workers may develop a rather close relationship to the agency. This means, for example, that they are personally known by agency employees and not simply constitute a number, that they frequently communicate to the agency, and that they develop a sense that the agency cares for them. 
However, the workers are perfectly aware that, in the end, they are just part of the agency's business model. Therefore, although the agency offers assignments, hence the chance to generate income, it does not provide any sense of membership or belonging, like would be the case with any 'real' employer.

Thirdly, in Denmark the so-called non-permanent temporary agency workers, who participated in our study, legally count as unemployed. However, they do not belong to the 'typical' unemployed, who do not engage in any work and fully rely on unemployment benefits. Instead, they are working and through their temporary work they also belong to the working population, at least somehow. Yet, they are not allowed the status of jobholders. For our participants, temporary agency work often means to shift between times during which they work at a user-firm and periods where they do not work. As a consequence, they are neither typically unemployed nor do they belong to the working population. In fact, revealing to others that they are temporary agency workers, they are often seen as someone who does not have a real job, meaning a permanent position. This signifies that to be a temporary agency worker is not always accepted by society.

However, these three notions played out differently for the workers depending on their individual situation, hence, their individual interpretation of being a temporary agency worker. Using age and work experience as criteria, we have been able to identify three groups. They help to exemplify the diversity within the individual experience of being betwixt-and-between as a temporary agency worker.

Some of them saw temporary agency work both as a chance to gain work experience, thus, an explorative phase (Garsten 1999), and as a period of transition into permanent employment. These workers are young, often unmarried, and usually do not have children. For them temporary agency work constitutes an opportunity to earn money because without work experience (some are also unskilled) it seems to be impossible to get a permanent employment. Three of them used temporary agency employment to bridge the time before starting to study at a university. Most of the young workers expect that through working as temporary agency workers their chances on the labor market will improve, hence, they will make the passage into permanent employment. It was, however, not in all cases clear whether they are aware that temporary agency work could also prove to become a dead-end, therefore, a permanent precarious situation. They are less concerned when the agency has no assignment to offer, since relying on unemployment benefits for them is still enough in order to make a living. "Regarding the economy I have learned to manage myself with a low income" (F9) as one of them put it. Given these circumstances, they less often care how they are treated by the user-firm. The lack of social integration does not constitute a big issue, as for them the assignment at the user-form is just a job. They see temporary agency work rather as a chance than perceiving it as a burden. In addition, they care less about which work they have to do and they can flexibly adapt their life to the demands this type of employment entails. Yet, they are also aware that this may become more difficult as soon as their life situation changes: "I am living with my boyfriend and we don't have any kids, so it is okay for now, but if I had a kid it would be difficult to work as a flexible employee. The uncertainty makes it very difficult to have a normal family life and working life" (I23). The younger temporary agency workers do not tend to have high expectations that the user-firm offers to them a permanent position. They rather conceive their work assignment as another step toward more work experiences, which some day enables them to find a permanent appointment. 
Others are married and have children who still live at home. Therefore the members who belong to this group feel that they have to care for the family and the investments they made (for example, their own house). They usually have work experiences and had permanent employments before. For them temporary agency work constitutes a stage of transition, a possibility to span the period where they do not have a permanent employment. At the same time temporary agency work constitutes a chance to again find entry into permanent employment. They are anxious that temporary agency employment may prove to become what Garsten (1999) referred to as a dead-end street. They feel committed to their family and experience a rather high pressure to generate a permanent income. One of them particularly emphasized the link between income and family life: "If you're working as temporary agency worker three months here or there, this has an effect on your economy and bad economy has a negative influence on the overall family relationships" (I14). They need to receive assignments from the agency, because relying on unemployment benefits is not an option, financial-wise. They are also rather sensitive with regard to how the user-firm treats them as with each new user-firm they see a new chance to use temporary agency work as a stepping-stone into permanent employment (Connelly and Gallagher 2004; De Cuyper et al. 2008). The members of this group prefer longer assignments at one user-firm since this provides some kind of stability. In addition, they fear to lose their present assignment, hence, feel more dependent on the user-firm. They are furthermore more dependent on the agency, since they are interested in receiving both well-paid and longer assignments. These workers see temporary agency employment as a burden, yet still as a chance to find their way back into permanent employment.

A third category of individuals, which we were able to identify, felt less economical pressure and was more flexible with regard to accepting shorter assignments and commuting longer distances. These workers are experienced with regard to both permanent employment and temporary agency work. Most of them are middle-aged persons with grown-up children. They know what it means to be a temporary agency worker and have learned to cope with the more problematic issues of this employment. Furthermore, they feel more accepted at the user-firm due to their experience and due to the circumstance that they usually do skilled work. Most of these workers understand their engagement with temporary agency work as transition into another permanent employment. For them temporary agency work constitutes a valuable and exciting experience. They actively use the opportunities temporary agency work offers: "You can decide when and how you want to work; I don't want to work for one week or less. I want to work for a longer period of time. This is very interesting with this job. You try the job before you want to start" (F8). Therefore, for the more experienced, temporary agency work constitutes less of a burden but most often a chance to again find a permanent position for the remaining time of their working life.

\section{Time-The Temporal Dimension of The Liminal TAW Experience}

\section{Temporary Agency Employment as a Period}

Most of the workers in our study understand their engagement in temporary agency employment as a passage into permanent employment. Therefore, most of them experience 
this work as a period of transition, a feasible way to find a permanent employment. As one of them expressed it: "I really want to find a permanent job, but I know that at the moment it is not possible so I have the chance to work as a temporary agency worker now" (K14). Indeed, many of them see temporary agency work as a possibility to find a permanent position during times of higher unemployment rates. "I am working as flexible employee because I am unemployed, I heard that $20 \%$ of the flexible employees find permanent job through flexible employment. So this is a good opportunity to find a permanent job" (C29). For some, however, temporary agency work may turn into a more permanent state of employment. Being in this type of situation for some time, they begin to realize that temporary agency work may reflect negatively on their chances to step into permanent employment. As one of them said: "Some of the firms have still the old mentality, they believe that if you worked as temporary agency worker you are not stable, so this could be a problem and I know that it exists" (J12). Not being perceived as a stable person, hence a reliable employee, is seen as an issue by a few of the workers as employers "might think why he is working in so many different places, what could be wrong with him" (J17). This insight, however, forms a sharp contrast to their expectation to use temporary agency work as a means to find permanent employment.

Relating the temporal dimension to how different individuals in our study experience liminality, we saw a variation of insecurity, ambiguity, and despair. As one of the younger and inexperienced expressed it: "I really don't have any higher expectations, because of my age and experience; I don't have a longer working experience, so my chances are low" (J8). For this person it was clear that the passage into permanent employment would last longer. Most of the younger and inexperienced workers in our study understood that gaining work experience through temporary agency work takes time. And most of them were willing to take their time qualifying for a permanent position in the future.

The workers, who had a family, were more desperate that this transition period may become more permanent. Frequently changing user-firms, thereby altering work and commuting times, affects their family life. Furthermore, they expressed a high uncertainty in terms of when they would receive their next assignment from the agency and where the agency would send them. It became apparent that they prefer more stable arrangements and therefore desperately hope to find a permanent appointment.

\section{Sudden Events of Liminality}

Despite the circumstance that the liminal experience of the temporary agency workers is related to the period of transition, there are various events during which they realize that they are in an in-between state. This realization often is associated with the feeling of being easily replaceable and unwanted by the user-firm (Garsten 1999). One of these frequently occurring events is the beginning of a new assignment at yet another user-firm. Being always new in the user-firm continually reminds the workers about their liminal state. "The working environment is just like the first day of school, most of the permanent employees are looking down to you, and it is not that bad but it always reminds you that you are an outsider" (D28). Such situations contribute to the awareness of not belonging to the user-firms' staff, hence, their work community. Similar moments can be found outside work. Planning holidays, for example, becomes difficult since one does 
not receive any income during this time because the worker does not work at a user-firm. In addition, taking holidays one risks that the agency offers beneficial assignments to another temporary agency worker. Therefore, every time the workers attempt to plan their holidays, they become aware of not sharing the benefits of permanent employment (i.e., paid holidays) or unemployment (disposability of one's time).

\section{Space-The Spatial Dimension of the Liminal TAW Experience}

\section{Specific Places of Experiencing Liminality}

We were interested in learning about the experiences temporary agency workers make while working at the user-firm. Even if we received many aspects beyond the direct work experience, most of our findings represent how they interpret their time at the user-firm(s). To this extent, the workplace or the many workplaces they had constitute the specific place where our participants experience that they do not fit into the category of permanent employees. It is at the workplace where they have to learn processes, products, work standards, and social standards anew. The workplace constitutes the location where the workers experience getting lower wages than permanent employees. It is at work where they sometimes are denied access to the IT-systems necessary for performing their work. And it is at work where the managers treat them differently because they constitute a temporary workforce. However, it is also while working at the user-firm where the temporary agency workers become pulled into extended circles of loyalty (Garsten 1999). Even if we argue that the workers do not develop a sense of belonging to either one of them, both the agency and the user-firm formulate the level of commitment and how the temporary agency workers ought to behave while working. With regard to the need to be adaptable: "You have to be independent, fast-learning and experienced ... The important thing is that you have to be an open-minded, friendly and social person, which is the first requirement from the agencies but also from the working places" (D29). Being adjustable, as a particular characteristic of being a temp, constitutes both a necessary and demanded requirement to survive at the different userfirms. At the workplace this becomes prominent because the work task does not always match one's qualifications. The firms and departments operate differently and not all firms are willing to thoroughly introduce the temporary agency workers to the work task, the work environment, and the people one meets at each user-firm. Hence, it is the workplace in the user-firm that forms the particular place where the liminal experience unfolded for our participants in terms of being between the agency and the user-firm and between employee and just a temp.

\section{Areas of Experiencing Liminality}

While the various experiences in the user-firm constitute the liminal experience with regard to the working life, the private life represents another spatial area where temporary agency workers experience to be in-between. Our findings show that the liminal state associated with being a temporary agency worker stretches into the workers' private life. Frequent changes of user-firms, an inherent part of temporary agency work, require 
the workers to repeatedly build their private lives around the employment. This is particularly relevant for those who live together with a partner or who have a family. As one worker put it: "you have to talk with your partner and adjust your daily life" (F6). For these workers in our study, planning holidays, scheduling due to short-term notices of new work assignments, commuting, investments in, for example, a second car are issues that need to be addressed more or less frequently. It is these issues of the private life that make the workers aware that they are not constituting the standard employee and that therefore their private life looks different from the lives of permanent employees. This constitutes a strain for the partnership as it is expressed by the following worker: “(Y)ou don't have the opportunity to plan your future, when you are working as flexible employee you have to be available all the time if you really want to work and earn money. From my personal experience, my partner is tired of this. If you can't go to work then someone else will take your spot so you don't have a job and income. So holidays and other social activities are very difficult to plan, you really don't know when you can have a holiday. You are forced to work and it is very irritating" (F19). Here it becomes apparent how the work life sheds into the private life, making the private lifezone one where the temporary agency workers experience their liminal situation as well.

\section{The Scale of the Liminal TAW Experience}

Temporary agency work constitutes an experience of being betwixt-and-between established categories (Garsten 1999). Smith (1998) refers to temporary agency workers as being "institutionally obscured" (p. 420), not fitting the institutionalized categories commonly applied to designate the position of employees in the labor market. Both authors address the circumstance that being a temporary agency worker means to be liminal. The above findings from our study elucidate that liminality always lurks around in the mind of temporary agency workers when they refer to their experience. Hence, temporary agency work goes along with experiencing some level of liminality. However, as our results also show, there are times and places where our workers became more aware of this. Sudden events or specific places raise the intensity of the liminal experience. Furthermore, some individuals, as indicated above, tend to have a more intense feeling of the issues that temporary agency work associates to them. Therefore, the scale of how our participants experienced liminality varied although a certain level of uncertainty and ambiguity seems to always be present.

\section{Discussion}

Referring to Turner's concept of liminality and its application in Organization Studies, we elaborated on the various dimensions of the liminal experience. Thomassen's (2009) work was particularly helpful in identifying the dimensions of 'types of subjects,' 'time,' 'space,' and 'scale' as useful to analytically unlock the liminal experience. These dimensions help to better understand the many ways in which liminality unfolds as an experience. We used the findings of an own empirical study in order to exemplify temporary agency workers' multi-dimensional experience of liminality. In doing so, we related to the seminal work of Garsten (1999) on the liminal experience of temporary agency 
workers. Exploring the workers' interpretations allowed us to illustrate to what extent their passage to permanent employment forms a liminal experience that develops along the dimensions presented in the theoretical framework. Emphasizing the transition into permanent employment we did not pay attention to the circumstance that temporary agency work could become a permanent precarious situation as expressed for example by Standing (2011). We did so, since the participants in our study continuously stressed that they perceive their current employment situation as a transition into a permanent position.

Our article contributes to the literature in two ways. Firstly, it contributes to the understanding of the complexity of liminality as a concept. Secondly, it contributes to comprehend the temporary agency workers' liminal experience as multi-dimensional.

\section{Liminality as Multi-dimensional Phenomenon}

Enhancing the understanding of the complexity of liminal experiences, we applied insights from political anthropology. We introduced the idea of the liminal experience as a multi-dimensional phenomenon. In doing so, we advanced our knowledge from previous studies of liminality in organizational contexts, which mainly follow Turner's original notion that liminality unfolds in time and space. We elucidated that the temporal dimension can be further divided into sudden moments, during which the sense of being liminal becomes heightened and longer periods or even epochs forming longer time frames, during which people experience themselves as liminal. These aspects have been addressed in previous research. For example, Sturdy et al. (2006) rendered business meals between consultant and clients as particular moments in-between work and leisure, Eriksson-Zetterquist (2002) studied the period of entering an organization as liminal stage, Ellis and Ybema (2010) addressed the rather permanent and mandatory liminality of inter-organizational relationship managers. Our framework contributes to situate previous research along the temporal dimension, thereby highlighting the various temporal aspects of the liminal experience. With regard to the spatial dimension, it is not only specific places but also broader areas or even countries where people can make liminal experiences. Hence, to be betwixt-and-between as a consultant is not only experienced during business meals in restaurants, like Sturdy et al. (2006) illustrate, but 'doing the consulting' constitutes a broader workspace outside the university or the consulting company where the consultants belong (Czarniawska and Mazza 2003). Therefore, elaborating the spatial dimension contributes to a better differentiation with regard to where liminality is experienced. In addition to time and space, we have been able to show that there are more dimensions, hence, more meanings of liminality for those who experience it. Types of subjects and, thus, differences in the liminal experiences for groups or individuals, constitute another dimension in order to understand that this experience has differing meanings. Furthermore, scale, and hence the intensity of the liminal experience, varies with regard to time, space, or types of subjects. Previous research occasionally referred to the intensity of the liminal experience. For example, Beech (2011) studied a period of organizational change, during which the participants experienced a high level of being in-between. However, the dimension of scale and therefore the degree of the liminal experience did not receive much attention so far. 
We argue that the analytical distinction that we introduced in this article, on the one hand, provides categories to situate prior and future research on liminal experiences. On the other hand, it constitutes a means to make better sense of how people experience liminality. For liminal personae it is important where and when they experience to be liminal, whether this constitutes a group experience or an individual one, and to what degree they experience to be in-between established social categories. Hence, the dimensions matter to the extent that they contribute to the particular meaning liminality has for people. In our study we were, for example, able to show that the temporary agency workers develop a heightened awareness of their in-between state during particular moments (beginning an assignment at a user-firm) and at specific places (the user-firm). We also demonstrated that to be betwixt-and-between has meaning for them as a group, even though it is experienced differently by different types of individuals. Therefore, comprehending how liminality unfolds along several dimensions enhances the understanding of the liminal experience as a sensation, which has many facets.

\section{Temporary Agency Workers' Liminal Experience as Multi-dimensional}

With regard to our contribution to temporary agency workers' liminal experience, we agree with Garsten (1999) that this type of temping constitutes a liminal space. Garsten (1999) wrote about temporary agency workers in Sweden and the US. She illuminated that their liminal state is associated with ambiguity in terms of where to belong and how to position oneself, uncertainty in terms of how the transition state may develop, and marginality in terms of the various disadvantages the liminal state brings. The workers in our study also lacked the structural bond that is created by a regular employment position, i.e., permanent employment. They had difficulties defining themselves as employees of the agency, even if the agency legally served as the employer. The workers also had problems to develop a sense of belonging to the user-firm since they continually experienced that the user-firm denies them this status. Additionally, most of our participants had strong hopes to find a permanent placement through temporary agency work similar to the workers in Garsten's (1999) study. However, they also expressed concerns that making the transition into permanent employment may turn out to become a rather long road. They were particularly uncertain whether they may be successful in getting the permanent employment state and, therefore in the future being able to benefit from the bonds created by the more regular employment position. However, a few workers expressed that, for them, temporary agency work was a choice to have the chance to receive interesting assignments, yet also some freedom to decide where and when to work. Finally, the workers in our study experienced various instances where they felt marginalized and disadvantaged compared to regular employees, hence, having few rights due to their liminal status (Beech 2011).

Applying a multi-dimensional focus on the liminal experience of the temporary agency workers, we have been able to further differentiate the meaning of being betwixtand-between. This enabled us to expand the understanding of temping as a liminal experience. As a group, temporary agency workers share certain experiences of being in a transition state that hopefully leads to (re-)enter permanent employment. As temporary agency workers, they are "separated from the traditional support networks, structures and arrangements of employment and urged to refer to themselves in planning their 
individual work biographies" (Garsten 1999, p. 616). However, as the participants in our study constituted different types of subjects, their individual experiences of the situation differed. Some accepted that this transition might last longer due to their lack of work experience. Others were more desperate, since they experienced temporary agency work as a burden, as a type of flexible employment that creates various social and financial problems. With regard to both space and time, our participants' experiences of being betwixt-and-between varied, particularly regarding its intensity. Overall, our findings demonstrate that who experiences liminality, where and when this experience manifests itself, and to what degree it manifests itself, constitute dimensions to meaningfully and comprehensively understand the liminal experience of temporary agency workers.

Furthermore, we were able to exemplify how the different dimensions are related to each other. Similar to Sturdy et al.'s (2006) notion of business meals as liminal timespaces, the liminal experience of temporary agency work unfolds as a combination of the temporal and spatial dimension. Certain events, situations, or contexts take place somewhere and within a shorter or longer time span. Hence, the workers experienced liminality along both time and space. However, we also demonstrated that the type of subject, hence, whether liminality is experienced as a group or on a more individual level, matters with regard to places and periods. Simply put, the period of being a temp and the various places where the workers become aware that they are different from the standard employment category unfold in various ways depending on whether the focus is on the group of temporary agency workers or on individual types of these workers. Finally, the degree to which the workers experience ambiguity, uncertainty, and marginality, again, is related to the other dimensions. We believe that exemplifying this relatedness sparks an initial understanding of how the dynamic experience of being betwixt-and-between is constituted.

\section{A Notion on Future Research}

Even though our findings help to illustrate the multi-dimensional liminal experience, we also believe that further empirical research is needed. Future studies should explore the various dimensions in other contexts of passages from one relatively stable state to another. In doing so, similarities and differences between various liminal experiences and the role the various dimensions play could be identified. Furthermore, liminality as a permanent state as expressed by Turner (1969) may form the target for future research. With regard to temporary agency work, it is well recognized that this type of employment could become a continual situation (Garsten 1999; Standing 2011). However, investigating how the dimensions of liminality unfold with regard to a continuous state of being betwixt-and-between could further illuminate this experience.

\section{References}

Ashford, S. J., George, E., Blatt, R. (2007) 'Chapter 2: Old assumptions, new work', The Academy of Management Annals 1(1): 65-117.

Barley, S. R., Kunda, G. (2006) 'Contracting: A new form of professional practice', Academy of Management Perspectives 19(1): 45-66. 
Beech, N. (2011) 'Liminality and the practices of identity reconstruction', Human Relations 64(2): 285-302.

Borg, E., Söderlund, J. (2014) 'Moving in, moving on: Liminality practices in project-based work', Employee Relations 36(2): 182-197.

Charmaz, K. (2006) Constructing grounded theory: A practical guide through qualitative analysis. London: Sage.

Connelly, C. E., Gallagher, D. G. (2004) 'Emerging trends in contingent work research', Journal of Management 30(6): 959-983.

Creswell, J. W. (2013) Qualitative inquiry and research design: Choosing among five approaches ( $3^{\text {rd }}$ ed.). Thousand Oaks, CA: Sage.

Cunliffe, A. (2002) 'Social poetics as management inquiry: A dialogical approach', Journal of Management Inquiry 11(2): 128-146.

Czarniawska, B., Mazza, C. (2003) 'Consulting as a liminal space', Human Relations 56(3): 267-290.

De Cuyper, N., De Jong, J., De Witte, H., Isaksson, K., Rigotti, T., Schalk, R. (2008) 'Literature review of theory and research on the psychological impact of temporary employment: Towards a conceptual model', International Journal of Management Reviews 10(1): 25-51.

Denzin, N. K. (1978) The research act (2 ${ }^{\text {nd }}$ ed.). New York: McGraw-Hill.

Ellis, N., Ybema, S. (2010) 'Marketing identities: Shifting circles of identification in inter-organizational relationships', Organization Studies 31(3): 279-305.

Eriksson-Zetterquist, U. (2002) 'Gender construction in corporations', in: Czarniawska, B., Hopfl, H. (eds.) Casting the Other: Production and Maintenance of Inequality in Organizations. London: Routledge: 89-103.

Felfe, J., Franke, F. (2010) 'Invited reaction: Examining the role of perceived leader behavior on temporary employees' organizational commitment and citizenship behavior', Human Resource Development Quarterly 21(4): 343-351.

Garsten, C. (1999) 'Betwixt and between: Temporary employees as liminal subjects in flexible organizations', Organization Studies 20(4): 601-617.

George, E., Chattopadhyay, P. (2005) 'One foot in each camp: The dual identification of contract workers', Administrative Science Quarterly 50(1): 68-99.

Gossett, L. M. (2006) 'Falling between the cracks: Control and communication challenges of a temporary workforce', Management Communication Quarterly 19(3): 376-415.

Guest, D. E. (2004) 'The psychology of the employment relationship: An analysis based on the psychological contract', Applied Psychology: An International Review 53(4): 541-555.

Håkansson, K., Isidorsson, T. (2012) 'Temporary agency work and organizational commitment', in: Furåker, B., Håkansson, K., Karlsson, J. C. (eds.) Commitment to Work and Job Satisfaction. Studies of Work Orientations. London: Routledge, 181-198.

Håkansson, K., Isidorsson, T., Kantelius, H. (2012) 'Temporary agency work as a means of achieving flexicurity?', Nordic Journal of Working Life Studies 2(4): 153-169.

Håkansson, K., Isidorsson, T., Strauss-Raats, P. (2013) 'Work environment for staffing agency workers-The physical and psychosocial work environment of staff provided by employment agencies', State of Knowledge Report, Swedish Work Environment Authority.

Jahn, E. J., Rosholm, M. (2010) 'Looking Beyond the Bridge: How Temporary Agency Employment Affects Labor Market Outcomes', IAB-Discussion Papers 9/2010, Institute for Employment Research Nuremberg.

Jenkins, R. (2011) Being Danish. Paradoxes of identity in everyday life (2nd ed.). Copenhagen: Museum Tusculanum Press.

Nørmark D. (2011) Kulturforståelse for stenalderhjerner [Cultural understanding for stone age brains]. Copenhagen: Det Andersenske Forlag.

Ryan, G. W., Bernard, H. R. (2003) 'Techniques to identify themes', Field Methods 15(1): 85-109. 
Scheuer, S. (2011) 'Arbejde på risikovilkår-Fleksibilitet og manglende tryghed [Work under risky conditions-Flexibility and poor security]'. LO-dokumentation, Nr. 1/2011, pp. 5-70.

Seale, C. (1999) The quality of qualitative research. London: Sage.

Smith, V. (1998) 'The fractured world of the temporary worker: Power, participation, and fragmentation in the contemporary workplace', Social Problems 45(4): 411-430.

Standing, G. (2011) The Precariat: The new dangerous class. London: Bloomsbury Academic.

Storrie, D. (2007) 'Temporary agency work in the European Union-economic rationale and equal treatment', in: Furåker, B., Håkansson, K., Karlsson, J. C. (eds.) Flexibility and Stability in Working Life. Houndmills, Basingstoke, Hampshire, and New York, NY: Palgrave Macmillan, 103-122.

Strauss, A. L. (1990) Qualitative analysis for social scientists (2 ${ }^{\text {nd }}$ ed.). New York: Cambridge University Press.

Sturdy, A., Clark, T., Fincham, R., Handley, K. (2009) 'Between innovation and legitimation-Boundaries and knowledge flow in management consultancy', Organization 16(5): 627-653.

Sturdy, A., Schwarz, M., Spicer, A. (2006) 'Guess who's coming to dinner? Structures and uses of liminality in strategic management consultancy', Human Relations 59(7): 929-960.

Szakolczai, A. (2009) 'Liminality and experience: Structuring transitory situations and transformative events', International Political Anthropology 2(1): 141-172.

Tempest, S., Starkey, K. (2004) 'The effects of liminality on individual and organizational learning', Organization Studies 25(4): 507-527.

Thomassen, B. (2009) 'The uses and meaning of liminality', International Political Anthropology 2(1): 5-28.

Trice, H. M., Beyer, J. M. (1993) The cultures of work organizations. Englewood Cliffs, NJ: Prentice Hall.

Turner V. (1967) The forest of symbols: Aspects of Ndembu ritual. Ithaca, NY: Cornell University Press.

Turner, V. (1969) The ritual process. Ithaca, NY: Cornell University Press.

Turner, V. (1970) 'Betwixt and between: The liminal period in rites of passage', in: E. A. Hammel, W. S. Simmons (eds.), Man Makes Sense (pp. 354-369). Boston: Little, Brown.

Van Gennep, A. (1960 [1909]) The rites of passage (Vizedom, M. B., and Caffee, G. L., trans.). London: Routledge and Kegan Paul.

Yüksekkaya, M. (2007) Uskrevne Regler på de Danske Arbejdsmarked [Unwritten rules of the Danish labor market]. Copenhagen: People's Press. 